\title{
Optimising product colour
}

\section{Document Version}

Accepted author manuscript

Link to publication record in Manchester Research Explorer

\section{Citation for published version (APA):}

Bruce, M., Benson, L., Oulton, D., Hogg, M., \& Wilson, J. (2001). Optimising product colour. Review of Progress in Coloration and Related Topics, 32, 29-35.

\section{Published in:}

Review of Progress in Coloration and Related Topics

\section{Citing this paper}

Please note that where the full-text provided on Manchester Research Explorer is the Author Accepted Manuscript or Proof version this may differ from the final Published version. If citing, it is advised that you check and use the publisher's definitive version.

\section{General rights}

Copyright and moral rights for the publications made accessible in the Research Explorer are retained by the authors and/or other copyright owners and it is a condition of accessing publications that users recognise and abide by the legal requirements associated with these rights.

\section{Takedown policy}

If you believe that this document breaches copyright please refer to the University of Manchester's Takedown Procedures [http://man.ac.uk/04Y6Bo] or contact uml.scholarlycommunications@manchester.ac.uk providing relevant details, so we can investigate your claim.

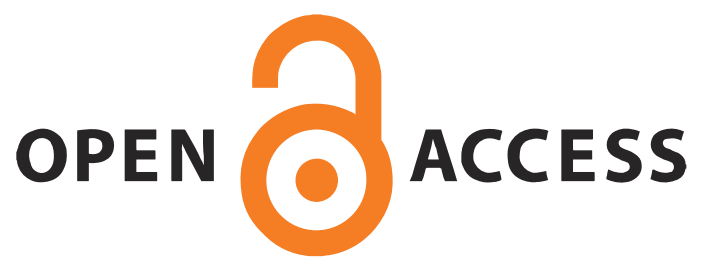




\section{Optimising Product Colour}

Louise Benson, David Oulton, Margaret Bruce, Jacquie Wilson \& Margaret Hogg UMIST

\section{Introduction}

The final colour of a product on sale to the consumer is the end result of a complex interaction of knowledge, guesswork, practical constraint, and marketing skill. Once the final colour is chosen, most of the problems associated with delivering the colour selected, under precise colour definition and control, at a reasonable cost, have been solved. Technical colour management is well served by accurate measurement and colour manipulation tools, and is well founded on tried and tested science. By contrast those managers, whose responsibility it is to deliver successful colour selection, can not appeal to much more than general principles, the dictates of fashion, and intuition, and have very few tools and measurement techniques to assist them.

The rapid development of computers and information processing technology offers the prospect of bringing together hitherto fragmentary and difficult to co-ordinate knowledge and precision colour technology in a concerted effort to improve the process of optimising product colour.

The following sections represent an overview of the research effort in this field, currently being carried out in the UMIST Department of Textiles.

\section{Colour and the consumer}

Colour has an important affect on consumer behaviour. It is well known that certain colours elicit feelings of excitement and other colours are considered restful and can make people feel tired. This article draws upon recent research to uncover the way in which colour affects consumer perceptions and its propensity to enhance products.

For clothing and textile manufacturers, achieving the right colour for the product and the retail environment is critical. If this is not done successfully, a company can lose market share and profit. Research that is being carried out at the Textiles Department at UMIST is looking at consumer perceptions of colour in high street fashion. Is there a stable colour palette for certain basic garments? Is there a pattern of colour choice in certain market segments? This article attempts to address the influence of colour on consumers.

\section{Consumer Perceptions}

The effects of various colours on consumer perceptions have been widely studied. Table 1 lists a number of colours and their common perceptions as well as examples of marketing stimuli that have utilised these colours to elicit certain perceptions.

Table 1: Common Perceptions of Colours

\begin{tabular}{lll}
\hline Colour & Perceptions & Marketing Examples \\
\hline Red & Powerful & First Alert Fire Extinguisher \\
& $\begin{array}{l}\text { Dangerous } \\
\text { Exciting } \\
\text { Passionate }\end{array}$ & \\
& Coca-Cola \\
Green & Calm & \\
& Natural & Gillette "sensitive skin" shaving gel \\
& Cool-cold & Healthy Choice food products \\
Blue & Sad & Nytol Herbal \\
& Respectful & Phillips' Milk of Magnesia laxative and antacid \\
& Cold & \\
Black & Prestigious & Mont Blanc pen \\
& Sophisticated & Johnnie Walker Black Label scotch \\
& Clean & \\
Clear & Pure & Palmolive Sensitive Skin dishwashing liquid \\
& Seltzers beverages \\
\hline
\end{tabular}


At one end of the light spectrum, colours with long wavelengths; reds, oranges and yellows, tend to elicit warm feelings in consumers. An example of a marketing application is the bright red seats that are found in many fast food restaurants. These establishments want to move customers quickly through the eating process. The bright colours encourage fast movements; consumers perceive the seats to be warm and tend not to linger.

At the other end of the light spectrum, short wavelength colours such as blues and greens are associated with coolness and encourage slower movements. The seats in an expensive restaurant are more likely to be blue or green to promote a more leisurely dining experience. However, there is also research that indicates it is not the colour, but the shade that is important in terms of evoking feelings of warmth or coolness.

\section{Colour and Advertising}

Colours in advertisements can be used to capture attention, portray realism and arouse feelings about an object. Printing types and other graphical elements also have significant motivational implications. The fastest reading rate and the fewest eye fixations were found to be associated with black print on a white background. Other combinations of colour giving fast reading rates were green on white, blue on white and black on yellow (Anastasi, 1979). Combinations giving slow reading rates were red on green and black on purple these could slow down reading by more than $50 \%$.

A study on the impact of colour in newspaper advertising concluded that a "median sales gain (on reduced-price items) of approximately 41 percent may be generated by the addition of one colour to black-and-white in retail newspaper advertisements. Figure 1 shows the relative attention attracting ability of black-and-white and of four colour magazine advertisements of different sizes. The impact of contrast can however reverse this. For example, if all advertisements in a magazine are in colour, a black-and-white advertisement will attract substantial attention.

\section{Figure 1: Colour and Size Impact on Attention}

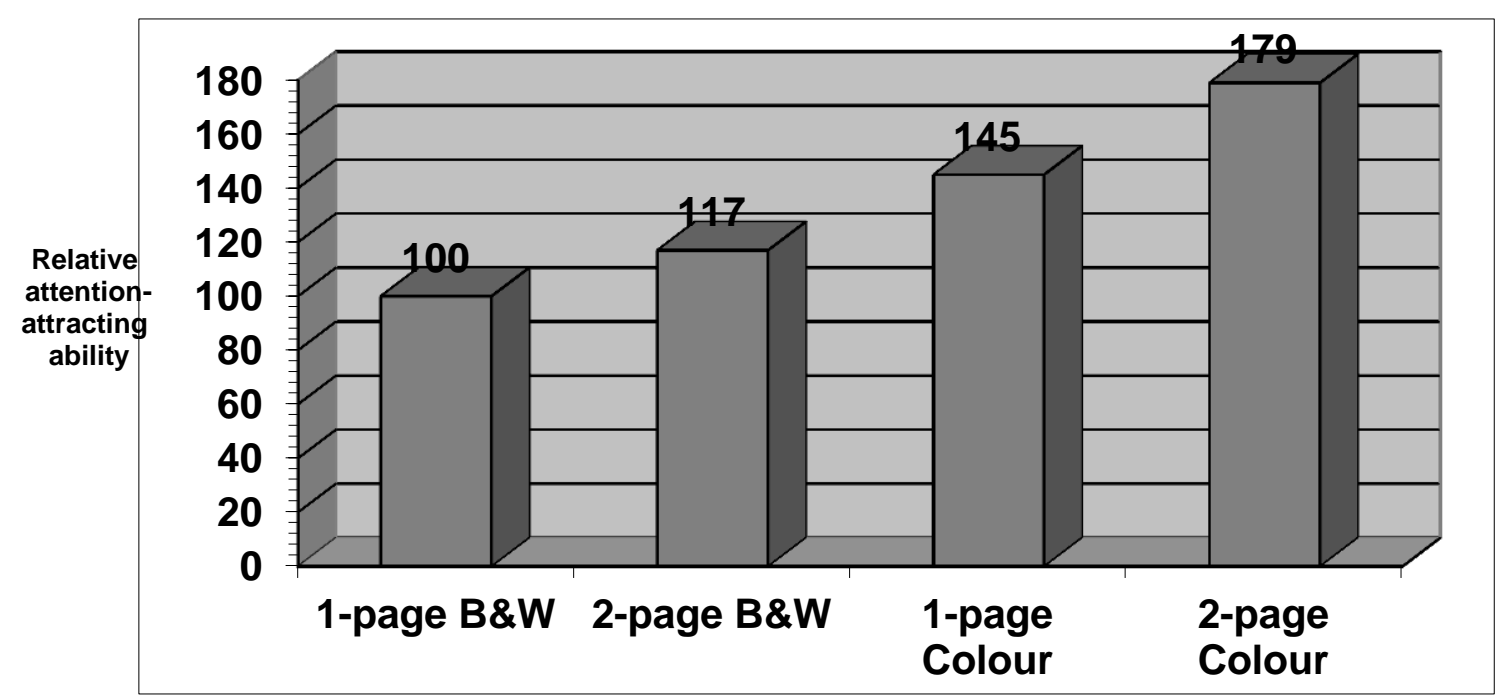

Source: Hawkins, Best \& Cooney, 1995

\section{Colour and Product Features}

Colour can be used to emphasise the attractive features of a product or used to create a suitable atmosphere. High technology products such as cameras are usually produced in black or metallic finishes. However, some cameras have been marketed with a less serious, "sporty" image in bright primary colours. Some products, such as cars come in a variety of colours, while others such as toothpaste are limited in their colour range. It would somehow seem incongruous to use black toothpaste.

A classic marketing example, where colour has been used to enhance product features, is Terry's All Gold. The colour of the product often leads to immediate recognition with consumers, even without 
seeing the name. Cadburys have achieved a similar subliminal effect by using the colour purple. It is however easy also for other companies to use/copy this recognition with a colour. For example, CocaColas' red can was instantly recognisable on a supermarket shelf until many supermarkets adopted the same colour scheme for their own-label cola. This copying resulted in recognition being detracted from Coca-Cola.

The latest trend to hit the skincare and bodycare market is a concentration on colour. In its purest form, colour therapy is a branch of alternative healing. Colour is a form of energy that vibrates at a higher frequency than heat or sound and therapists believe that it has a marked effect on consumers. Top cosmetics companies are now harnessing the positive effects of colour for new lines, the idea being that if the colour of a product can improve moods, the physical benefits of its formulation may also be enhanced. "Mood-mapping" techniques are being used to monitor sensory and emotional reactions to the colour of products. Companies such as Lancôme and Boots have already adopted this approach with products such as blue cleansers and bath oils, green toning lotion and yellow shower gel.

\section{Colour in the workplace}

Colour can be used in the workplace to create pleasant surroundings and to put across and reinforce safety messages. When planning the colour scheme or décor for a room it is important to consider the use to which the room will be put. For repetitive and monotonous activities the overall décor should be made more stimulating by providing small areas of bright colours. A large working area can be divided into smaller identifiable segments by using different colour schemes that complement each other. Where mental concentration is a necessary feature of office life, the colour scheme should be light in shade and non-intensive.

The effects of colours on the psychological state of the individual should also be considered, because some colours act as a stimulant while others act as a depressant. A dark blue ceiling may appear to be refreshing to begin with, but in time the perceived coldness may become an irritant. The psychological effects of different colours on the individual are tabulated in Table 2.

\section{Table 2: Psychological effects of different colours}

\begin{tabular}{|c|c|c|c|}
\hline Colour & Psychological Effect & Temperature Effect & Distance Effect \\
\hline Violet & $\begin{array}{l}\text { This colour can make the } \\
\text { individual feel aggressive } \\
\text { and tired }\end{array}$ & Cold & Very close \\
\hline Blue & $\begin{array}{l}\text { A feeling of restfulness is } \\
\text { often an affect of using this } \\
\text { colour }\end{array}$ & Cold & Further away \\
\hline Brown & $\begin{array}{l}\text { Excitement is associated } \\
\text { with this colour }\end{array}$ & Neutral & Claustrophobic \\
\hline Green & $\begin{array}{l}\text { This can be a very restful } \\
\text { colour }\end{array}$ & Cold/neutral & Further away \\
\hline Yellow & $\begin{array}{l}\text { Excitement is associated } \\
\text { with this colour }\end{array}$ & Very warm & Close \\
\hline Orange & $\begin{array}{l}\text { Excitement is associated } \\
\text { with this colour }\end{array}$ & Very warm & Very close \\
\hline Red & $\begin{array}{l}\text { This colour can be very } \\
\text { stimulating }\end{array}$ & Warm & Close \\
\hline
\end{tabular}

Source: McKenna, 1994

\section{Colour and Store Design}

The colours within a store are also sources of potential influence on both consumers' perceptions and behaviour. They act on consumers in a similar way in a retail location as they do in the workplace. Warm colours, such as red and yellow appear more effective in physically attracting people, relative to cooler colours of green and blue. In one study in which subjects were allowed to determine how close they sat to a coloured wall, the distance was much shorter for warm than cool colours. Nonetheless, subjects rated retail interiors using cooler colours as more positive, attractive and relaxing than those using warmer colours. The researchers concluded that warmer colours were most suitable for a store's 
exterior colour or display windows as a means of drawing consumers into the store (Bellizi, Crowley \& Hasty, 1983).

\section{Cultural Differences}

Colours have different connotations and traditional uses across cultures. Table 3 shows the connotations of certain colours in different cultures.

\section{Table 3: Colour Connotations}

\begin{tabular}{ll}
\hline Colour & Connotation \\
\hline White & Symbol for mourning or death in the Far East. \\
& Associated with happiness and purity in the United States. \\
Associated with death in many Latin American countries. \\
Purple \\
Connotations of femininity in Holland. \\
Associated with masculinity in Sweden and the United States. \\
Used to designate jungle areas where there is danger and disease in \\
Malaysia. \\
Unlucky or negative in Chad, Nigeria and Germany. \\
Positive in Denmark, Romania and Argentina. \\
Brides wear red in China, but it is a masculine colour in the United Kingdom \\
and France \\
Yellow flowers are a sign of death in Mexico and are associated with \\
infidelity in France. \\
White lilies are linked to death in the UK \\
Yellow
\end{tabular}

In China, white is associated with death. Most business travellers were shocked during the inauguration of United's concierge services for first class passengers on its Pacific Rim routes, as to mark the occasion, each concierge was proudly wearing a white carnation.

In Malaysia, green is used to designate jungle areas where there is danger or disease. A manufacturer of water-recreation products lost heavily in Malaysia because the company's predominant colour was green.

When designing advertisements and packages, marketers must be careful to avoid using colours that will send the wrong messages to the consumers of another culture. Many companies use different colours within certain cultures.

\section{Colour Trends}

The importance of colour has given rise to what is in effect a colour industry. In a given year, certain colours appear to be "fashionable" and to show up again and again in clothing, home furnishings, cars and many other items. These favoured colours tend to disappear as fast as they appear as they are replaced by another set of "fashionable" colours the next year or season.

The colour choices of consumers are affected by these trends. One simple reason is that the colours available in the stores that consumers patronise will largely limit their choices. Few people however realise the extent to which these "fashionable" colours result from deliberate choices made by industry experts, in a process known as colour forecasting.

Colour experts in groups meet periodically to estimate what colours will best reflect a season in one year, in five years, and sometimes even ten years (Mundell, 1993). Members make colour predictions based on cultural and social trends, and these recommendations are then used by manufacturers to plan production. 
Marketers need to be aware of the influence that colour has on the consumer in order to deliver suitable colours to their customers. Even a slight difference of shade from the requirements of the consumer can be catastrophic to the manufacturer. Is there a range of colours on a colour palette that a clothing company can use each season, by simply adjusting the shades? This has worked for designers such as Armani, who uses a palette of basic colour such as grey, blue, black, beige and white. Could this simplistic range of colours ever work for high street retailers?

\section{Colour Definition}

Colour can be described and defined with a wide range of precision levels. Kelly defines six levels of precision in his 'Universal Color Language' (Kelly 1976).

\begin{tabular}{|c|c|c|c|c|c|c|}
\hline \multicolumn{4}{|c|}{ Colour name designations } & \multicolumn{3}{|c|}{ Number and/or letter colour designations } \\
\hline $\begin{array}{l}\text { Level of fineness } \\
\text { of colour } \\
\text { designation }\end{array}$ & $\begin{array}{l}\text { Level } 1 \\
\text { (least } \\
\text { precise) }\end{array}$ & Level 2 & Level 3 & Level 4 & Level 5 & $\begin{array}{c}\text { Level } 6 \\
\text { (most precise) }\end{array}$ \\
\hline $\begin{array}{l}\text { Number of } \\
\text { divisions of } \\
\text { colour solid }\end{array}$ & 13 & 29 & $267^{\mathrm{a}}$ & $943-7056^{\mathrm{a}}$ & $\approx 100,000$ & $\approx 5,000,000$ \\
\hline $\begin{array}{l}\text { Type of colour } \\
\text { designation }\end{array}$ & $\begin{array}{l}\text { Generic } \\
\text { hue names } \\
\text { and } \\
\text { neutrals }\end{array}$ & $\begin{array}{l}\text { All hue } \\
\text { names and } \\
\text { neutrals }\end{array}$ & $\begin{array}{l}\text { ISCC-NBS } \\
\text { All hue } \\
\text { names and } \\
\text { neutrals with } \\
\text { modifiers }\end{array}$ & $\begin{array}{l}\text { Colour-order } \\
\text { systems } \\
\text { (collections of } \\
\text { colour standards } \\
\text { sampling the } \\
\text { colour solid } \\
\text { systematically) }\end{array}$ & $\begin{array}{l}\text { Visually } \\
\text { interpolated } \\
\text { Munsell } \\
\text { Notation }\end{array}$ & $\begin{array}{l}\text { CIE }(x, y, Y) \text { or } \\
\text { instrumentally } \\
\text { interpolated } \\
\text { Munsell } \\
\text { Notation }\end{array}$ \\
\hline $\begin{array}{l}\text { Examples of colour } \\
\text { designation }\end{array}$ & Brown & $\begin{array}{l}\text { Yellowish } \\
\text { brown }\end{array}$ & $\begin{array}{l}\text { Light } \\
\text { yellowish } \\
\text { brown } \\
\text { (centroid \#76) }\end{array}$ & $\begin{array}{l}\text { Munsell } \\
\text { 10YR 6/4 }\end{array}$ & $\begin{array}{l}9.5 \mathrm{YR} \\
6.4 / 4.5\end{array}$ & $\begin{array}{l}X=0.395 \\
Y=0.382 \\
Y=35.6 \text { or } \\
9.6 Y R 6.4_{5} / 4.3^{b}\end{array}$ \\
\hline General applicability & & $\leftarrow \mathrm{S}$ & $\begin{array}{l}\text { Increased finen } \\
\text { cal expression o }\end{array}$ & $\begin{array}{l}\text { s of colour designa } \\
\text { colour trends (roll- }\end{array}$ & method) $\leftarrow$ & \\
\hline
\end{tabular}

Source: Kelly (1976)

At each level of increasing precision, more colours can be identified unambiguously. Colour naming, with or without physical samples to illustrate the colour concerned, is widely adopted in the fields of colour forecasting, design, printing, and the graphic arts, as a method of colour definition and communication.

A few thousand unambiguous colour definitions are possible using naming systems and colour atlases (Kelly's levels 1 -4). By contrast, technical colour management and production control in the textile, plastics, paint, and vehicle construction industries for example, use colour definitions based on spectrophotometry and the CIE system (Billmeyer and Saltzman). This gives colour definitions which are an order of magnitude more precise than those provided by colour atlases and colour naming.

The necessity for very precise colour definition arises from the need to match customer requirements for colour to within a just visible difference. In terms of marketing, all components of a product, coordinated products, and batches of products must be perceived by the end user to have uniform colour or controlled colour variation.

\section{Uses of Precise Colour Definition}

Traditionally, use of precise colour definition has been limited to those areas of technical colour management described above. Recent research at UMIST ( Oulton et al.1996) has been aimed at extending the use of precise colour definition into the fields of design, colour communication (Bruce et al. 2001), colour range development, (Oulton 1991), and the use of calibrated colour imaging to define and specify the effects of texture on colour appearance (Oulton et al. 1998).

It has been noted during the above research that consumer choice of colour may have features that can only be revealed by detailed analysis using precision colour measurement. As an example we refer to the 'classic' colour Navy Blue. Two companies participating in the research find that, with thirty plus distinct variations of navy blue, one or two out-sell all the others by a significant margin. It was also found that very minor changes in a stock-range powder blue are sufficient to distinguish 'this year's' new palette from last year's range, and make the old product look dated and in need of replacement. 
Calibrated colour imaging has opened up a wide range of applications for precision colour definition. The starting point is the ability to reproduce at will on a computer screen, a very wide range of CIE colour definitions with an accuracy approaching that required to give a perfect visual screen-to-sample match, for any of 16.7 million colour definitions. The screen image is a visual colour match, to a physical sample which has the same CIE colour definition.

Using calibrated screens, the visual effect of very small changes in colour specification can be simulated and used in colour co-ordination and colour range development, without having to do the many costly and time consuming dyeing needed, if physical comparisons are used. This has enabled substantial reductions in lead-time in developing new shade ranges (Oulton 1991).

A coloured image of a textile product, with texture, high-light and shadow effects, can be reproduced on a colour-calibrated computer screen. This allows the point-by-point analysis of colour as it varies across the surface texture. Individual point-colour variation down to the 100 Micron level (100 points per square mm) has been analysed (Oulton \& Porat 1997). An image of a typical colour-woven textile fabric, with strong surface texture, was found to contain in excess of 100,000 distinct colours. Even a nominally single shade solid-dyed texture gives several thousand point-colour definitions.

Using CIE colour definition of image content, it has been found that individual textures have characteristics, which are independent of their measured or intrinsic colour. A given texture simulation on the computer screen, can thus be altered substantially in colour while maintaining an effective simulation of the texture, and its contribution to appearance.

Image analysis allows the intrinsic colour underlying the visual appearance of a textured material to be deduced. The output from the computer is a synthetic spectral reflectance curve, which can be used to generate an appropriate matching colorant formulation. It is thus possible to communicate a precise colour specification electronically to any dyehouse with a colorant formulation computer. At the local dyehouse a dyeing can then be reproduced that is a close visual match to the original screen image. In an exercise involving seven dye-houses on four continents, and four different materials, precisely coordinated colour was reproduced, which was a good match to the colour chosen on screen at the beginning of the trial.

\section{Colour Communication and Collaborative Design Networking}

In addition to reproducing the colour appearance of the texture or product, the image can be encoded, transmitted, and reproduced visually on a remote computer screen anywhere in the world. The remote computer will give visually correct colour reproduction of the image seen on the transmitting computer, due to calibration of the two screens, and common use of CIE colour definition. This principle is the basis of the 'Imagemaster' system, developed at UMIST during the project (Oulton \& Porat 1997). Imagemaster can store, retrieve, and manipulate items from libraries of colours, garments, textures, and products of all types. New product development can then include a wide range of colour / texture combination evaluations, by manipulating images of texture with alternative colours.

The networking of computers has now reached a level of maturity, which enables all those concerned with colour to collaborate by communication of designs, colour ideas, specifications, and product colour definitions (spectral reflectance curves). Laboriously produced swatches and sampling can be reduced to the minimum. There is unfortunately no substitute for a real product, when assessing handle, drape and final three-dimensional appearance.

As colour communication is speeded up, and made more precise fashion prediction, marketing, range development, and consumer choice analysis can all be brought together into a single product optimisation process. The technical aspects of colour, including cost, and performance can be optimised in parallel, and associated colour problems such as co-ordinating the packaging and display environment design can in principle also be integrated into the collaborative process.

A future is envisaged in which the designer can if required interact and optimise colour choice in collaboration with the dyer and buyer, over the colour communication network. The marketers will have in-depth intelligence of those colours which sell and those colours which do not. Presentation of photo-realistic images of products yet to be made is now possible, with the knowledge that they can be 
made if they produce a good consumer reaction. Test marketing may in future be done in many instances by measuring consumer reaction to such colour-calibrated images.

Minor subtle adjustments as well as new colours can be selected and discussed for feasibility with production units prior to committing fabric (establishing optimum cost, performance, and metameric properties for example). The many coloured components present in say a motor car interior and exterior design can be fully co-ordinated in specification, in many colour ways if necessary.

The two and three-dimensional aspects of design, currently the province of specialist technical designers, and design software, are predicted to become integrated into a comprehensive collaborative design network, with free image interchange in standard digital formats and CIE co-ordinate specified colour.

\section{The Dominance of Classic Colours}

A fitting subject for research, is the nature of fashion colour, and the classic colours that persist in popularity. Is it possible to discover new classics? Can extrapolation be made to find them? Are there 'durable' colours, which given an occasional rest, will come back into fashion again and again? Can consumer 'colour fatigue' be related to Hue or Chroma or Lightness? How can the contribution of Colour Psychology, economic conditions, and national mood be assessed? How do the many sources of fashion colour prediction compare, for uniformity of prediction, and accuracy in the event? Is fashion prediction a self-fulfilling prophecy? Is there a predictable or at least definable basis for quantifying such terms as colour harmony, contrast, tonality and the like?

Answers to some of these questions are beginning to emerge using the new computer-based colour definition and visualisation tools now available, and interaction between designers, colour scientists, and experts in management and marketing.

\section{Research at UMIST Department of Textiles}

The penalties for getting a colour range out of balance, or plain wrong for a given product are severe. It is not our intention to teach range managers there job, rather, we seek to give them new tools and knowledge to make that job easier.

At UMIST the complementary disciplines of Management, Marketing, Colour Science and Computing are being combined in a multi-disciplinary attempt to solve at least some of the questions posed. So far we have put in place new colour visualisation and communication tools, and made a start on analysing fashion colour predictions. Current research is addressing the underlying influences of consumer choice on one hand and precision colour imaging on the other.

Research usually makes progress either by developing and applying new tools to old problems, or by crossing inter-disciplinary boundaries to find new problems that can be solved with existing tools. Any researcher looking for interesting topics in the field of colour will not be short of challenges if they address some of the above questions. 


\section{References}

Anastasi, A., Fields of Applied Psychology (second edition), McGraw-Hill, Tokyo, 1979.

Bellizi, Joseph A., Crowley, Ayn E. and Hasty, Rondla W. "The Effects of Color in Store Design," Journal of Retailing 59 (Spring 1983), P21-45.

Bruce et al. 2001, "Predicting the Future: An Overview of the Colour Forecasting Industry"

M.A.Bruce, M.K.Hogg, and D.P.Oulton. The Design Journal 2001 Vol.4 Issue 1, pp 15 - 31. Publ. by Gower press, Farham UK.

Crowley, Ayn E., “The Two-Dimension Impact of Color on Shopping,” Marketing Letters, 4, 1993, p59-69.

Engel, James F., Blackwell, Roger D. and Miniard, Paul W., Consumer Behavior, The Dryden Press, Orlando, 1995. P801-802.

Hawkins, Del, Best, Roger and Coney, Kenneth, Consumer Behavior: Implications for Marketing Strategy, Richard D. Irwin, Inc., 1995, p53-44, 242-243.

McKenna, Eugene, Business Psychology and Organisational Behaviour, Lawrence Erlbaum Associates, Hove, 1994, p66, 121-122.

Mundell, Helen, "How the Color Mafia Chooses Your Clothes," American Demographics (November 1993), P21.

Oulton 1991. "Colour range generation using precise on-screen colour”, Proc. CNR. International Conference 'CAD-CAM in the textile industry' COMO, Italy, April, 1991.

Oulton et al.1996 “Building a Precision Colour Imaging System” D.P.Oulton, J.Boston, \& R.Walsby, Proc. IS\&T/SID $4^{\text {th }}$ Int. Imaging Conf. Scottsdale Arizona, pp14-19 Nov 1996.

Oulton et al. 1998 "Colour Systems for the Analysis and Definition of Surface Texture, and its Effect on Colour Appearance", D.P.Oulton, E.Peterman, \& A.W.Bowen. Proc. $5^{\text {th }}$ Intl. Conf. 'Colour and Colorimetry' pp 65-75, Sept 1998, BRDO Slovenia ISBN 86-435-0244-8. Publ. University of Maribor, Smetanova 17.2000, Maribor Slovenia.

Oulton \& Porat 1997 "Colour Systems for Texture in Textile CAD" EPSRC Project No. GR/J 91852 Final Report. D.P.Oulton \& I.Porat. UMIST 1997.

Solomon, Michael R., Consumer Behavior, Prentice Hall, Inc. New Jersey, 1996, P62.

Wells, William D., Prensky, David, Consumer Behavior, John Wiley \& Sons, Inc., Canada, 1996, p117, 265-266. 